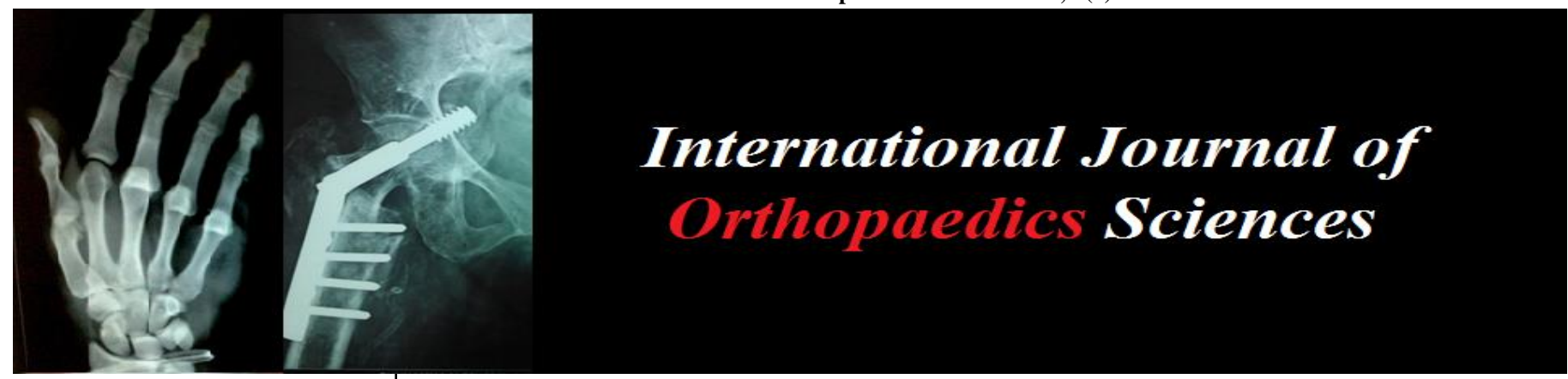

E-ISSN: 2395-1958

P-ISSN: 2706-6630

IJOS 2019; 5(4): 606-612

(C) 2019 IJOS

www.orthopaper.com

Received: 04-08-2019

Accepted: 06-09-2019

Dr. Hemant Parekh

MS DNB (Orthopaedics),

Professor, Department of Orthopaedics, Smt. Kashibai

Navale Medical College and

General Hospital, Narhe, Pune,

Maharashtra, India

Dr. Aniket C Deshmukh

Postgraduation Resident,

$3^{\text {rd }}$ Year, Smt. Kashibai Navale

Medical College and General

Hospital, Narhe, Pune,

Maharashtra, India

Dr. Shriram Devkate

Postgraduation Resident,

$3^{\text {rd }}$ Year, Smt. Kashibai Navale

Medical College and General

Hospital, Narhe, Pune,

Maharashtra, India

Dr. Aditya Naiknimbalkar Postgraduation Resident,

$3^{\text {rd }}$ Year, Smt. Kashibai Navale Medical College and General

Hospital, Narhe, Pune,

Maharashtra, India
Corresponding Author: Dr. Hemant Parekh MS DNB (Orthopaedics) Professor, Department of Orthopaedics, Smt. Kashibai Navale Medical College and General Hospital, Narhe, Pune, Maharashtra, India

\section{To assess functional outcome of posterior cruciate ligament tibial avulsion fracture treated with open reduction internal fixation by cancellous screws with washer through Burk's and Schaffer's posteromedial approach}

\author{
Dr. Hemant Parekh, Dr. Aniket C Deshmukh, Dr. Shriram Devkate, \\ Dr. Aditya Naiknimbalkar
}

DOI: https://doi.org/10.22271/ortho.2019.v5.i4k.1739

Abstract

Posterior Cruciate Ligament (PCL) tibial avulsion fracture is relatively rare injury. PCL is main posterior stabilizer of the knee. There is controversies in literature about surgical indication for PCL Injuries treatment. But if PCL tibial avulsion fracture left untreated if may leads to chronic instability and early degenerative changes. Numerous technique for treatment of PCL tibial avulsion Fracture have been Described in literature from closed reduction to definite fixation, both open and arthroscopically assisted fixation. Objective of study, to access functional Outcome of Posterior cruciate ligament tibial avulsion fracture treated with open reduction internal fixation by cancellous screws with washer through Burk's and Schaffer's Posteromedial approach. Functional outcome measure with Lysholm score. Total thirty patient cases of PCL tibial avulsion fracture were included for study from January 2015 to November 2018, which were operated in our Institute Smt. Kashibai navale medical college and General hospital, Narhe, Pune. Assessment with help of clinically, Radiologically and functional outcome by Lysholm score. We got result like, age of the patients was between 20-50years (Avg. 35.6years).Total follow up months between 6-12 months (Avg. 8.3 Months). Preoperative Lysholm score between 25-35 (Avg. 29.8). Postoperative Lysholm score between 84-100 (Avg. 96 which is excellent). Male to Female incidence ratio was 2.7:1. There were 3 patients with Postoperative Laxity with Mild grade $(<5 \mathrm{~mm})$. There three patients with Residual pain after last follow up but on radiographic study found union. There Four patients with Superficial infection which were treated with oral antibiotics and cure that only no need operative procedure for same. We concluded as, PCL tibial avulsion treated with open reduction and internal fixation by one cancellous screws with washer through Burk's and Schaffer's posteromedial approach leads to excellent clinical results, radiological findings and functional outcome.

Keywords: PCL avulsion fracture, Burk' and Schaffer's approach

\section{Introduction}

Posterior cruciate ligament tibial avulsion fracture relatively uncommon injury. 20\% incidence rate of PCL tibial avulsion fracture of total ligament injury in knee joint. PCL is stronger among two cruciate ligaments. Anatomically PCL acts as a posterior knee stabilizer and limits the posterior tibial translation ${ }^{[10,20,22,30]}$. Most common mode of injury is due to road traffic accidents, sport activity and domestic fall accident ${ }^{[2]}$. Main mechanism of injury involved in PCL Injuries is the dashboard injury, from direct trauma to the tibia at anterior portion with the knee in flexion ${ }^{[13]}$. In sport activities the main mechanism of injury is sudden excessive flexion of an extended knee or fall over a flexed knee ${ }^{[12]}$.

PCL serve as primary restraint to posterior translation of tibia over the femur and also as a secondary restraint to internal and external rotatory force over the knee ${ }^{[27]}$. If left untreated, PCL deficient knee is leads to abnormal loading and is predisposed to cartilage damage and early degeneration with chronic instability ${ }^{[3]}$.

Torisu et al have quoted that PCL tibial avulsion fracture neglected beyond 11 weeks, have poor results ${ }^{[26]}$. 
Griffith et al strongly advocated fixation of displaced PCL tibial avulsion fracture to avoid the morbidities associated with PCL avulsion fracture non-union ${ }^{[9]}$.

PCL tibial avulsion injury differ from other PCL injuries in that they are easily diagnosed on Standard radiographs where bony fragments may be visible.

Over the past few years, a lot has been discussed about treating PCL tibial avulsion fracture. The incidence of this subset of injury had increased over the past few years, due to advance diagnostic techniques like standard plain radiograph antero-posterior view and lateral view, CT scan and MRI scan and increased awareness of the necessity to treat these fractures. Although conservative management is no longer advocated for PCL tibial avulsion fracture, there is various debate on favourable choice of surgical fixation techniques likes open or arthroscopically with cancellous screws, Stain steel wires, absorbable screws, suture anchor, straddle nail, sutures. While open reduction internal fixation have been in the forefront for lots of years, recent advances in arthroscopic techniques have encouraged more surgeon to option for arthroscopic assisted fixation. Arthroscopic repair is technically more challenging, require specialized equipment and has a long learning cure ${ }^{[8]}$. Although both techniques have their advantage and disadvantage, it is usually at the discretion of the operating surgeon toward choosing the technique of his choice and comfort.

Aim of the Study is to assess functional outcome of Posterior Cruciate ligament tibial bony avulsion fracture with open reduction internal fixation by one cancellous screws with washer through Burk's and Schaffer's Posteromedial approach.

\section{Material and Methods}

From January 2015 to November 2018, Thirty patients with PCL tibial avulsion fracture injury presented at Smt. Kashibai Navale medical college and general hospital, Narhe, Pune were included in study.

The Mode of injuries may be Road traffic accidents, sports activities or domestic fall accidents in which mechanism of injuries may be dashboard injury, hyper-flexion injuries.

The Injury was diagnosed by clinical examination were patients subjected with Lachman test, anterior drawer test, posterior drawer test for integrity of cruciate ligaments. The collateral ligaments assessed with varus and valgus stress test in extension and in 30 degree flexion. The dial test and external rotation recurvatum test were performed to assess the associated posterolateral ligament complex insufficiency.

Patients also subjected to radiological investigations to confirm diagnosis like Standard plain radiograph Anteroposterior view and Lateral view, CT scan and MRI scan. CT scan for document size of the fragment and MRI to rule out other ligaments injuries.

All the patients were examined again under anaesthesia in the operative room prior to surgical intervention.

\subsection{Surgical Technique}

Preoperative antibiotics (1.5 gm cefuroxime, intravenous) was administered in all the cases after sensitivity testing, 30 mins prior to skin incision. The operative procedure were performed under spinal anaesthesia with tourniquet control.

The patients were positioned in prone position. Skin incision was made over posterior aspect of knee through Burk's and Schaffer's approach with horizontal limb over popliteal crease and vertical limb on medial aspect of medial head of gastrocnemius. The deep fascia over the Medial head of gastrocnemius was incised as skin incision and interval between medial head of gastrocnemius and semimembranosus tendon was identified. The Dissection was carried bluntly with finger until the posterior capsule of knee joint was reached. Care is taken to identify and isolate the motor branch of tibial nerve and the middle geniculate artery. Whenever necessary middle geniculate artery was ligated. The Medial head gastrocnemius was retracted laterally, thus protecting the neuro-vascular bundle of popliteal fossa. The posterior aspect of femoral condyle and proximal tibia could be palpated at this stage. Slight knee flexion was done in almost all the cases for better visualization. Recession of tendinous origin of medial head gastrocnemius was carried out whenever necessary for enhancing exposure. The posterior joint capsule was incised vertically to access the content of posterior intercondylar notch and tibial attachment of posterior cruciate ligament. The PCL tibial bony avulsion fracture fragment was reduced anatomical and secured with Kirschner's wire (K wire) and positioning verified under fluoroscope. The PCL tibial bony avulsion fracture fragment was then fixed with one Cancellous partially threaded screw with washer. Position of fragment again assessed under fluoroscope and if found adequate the wound was washed and closed over drain. Patients were discharge on postoperative day 12 with suture removal.

\subsection{Post-Operative protocol}

The limb was kept Immobilized using a long knee brace for 6 weeks. Postoperative two doses of antibiotics was given (1.5 gm cefuroxime, intravenous). Quadriceps strengthening was started from the $2^{\text {nd }}$ postoperative day. Passive knee bending was started after suture removal on $12^{\text {th }}$ Post-operative day. Active Knee range of motion was started 3 weeks after surgery. Partial weight bearing was allowed after 6 weeks and full weight bearing was allowed depend on Radiographic finding of fracture fragment union near about 12 weeks when the brace was also discarded. Return to heavy activities, such as running and sport, were allowed only after 6-9 months.

Patient were regularly followed up every 14 days in first month then every month for next 6-9 months. At every follow up, patients were assessed clinically and radiologically. Laxity assessed with Drawer test and radiological stress view. Final functional outcome measure with Lysholm scoring system.

\section{Results}

Of total Thirty Patients of PCL tibial avulsion fracture in this study male were $73 \%$ as compared to the female who counted to $27 \%$. 24(80\%) patients had Road traffic accidents while $4(13 \%)$ patients with Sports activities accident and remaining $2(6 \%)$ patients with domestic fall accidents. Patients Falling age group Between 20year to 50years of age (average $35.6 y e a r s)$. Out of thirty patients $17(56 \%)$ patients were affected on right side remaining $13(43 \%)$ patients with left side affected. Duration between trauma and fixation is Average 8.9 days (7-12 days). Patients were followed up till 8.3 months (6-12 months).

The Lysholm score ameliorated from an Average 29.8 preoperative to 96 postoperative, $\mathrm{p}$ value $<0.001$ with Paired $t$ test. Pre-operative posterior drawer testing showed that all had sag and the drawer test was positive either in grade $1(<5 \mathrm{~mm})$, grade $2(6-9 \mathrm{~mm})$ or grade $3(>10 \mathrm{~mm})$. Postoperative 3 cases had Mild grade 1 laxity.

In this study 28 patients united radiologically within 12 weeks. Average time of union was 10 weeks. Two case 
developed delayed union(more than 16 weeks). There were 4 Patients with superficial infection which healed with oral antibiotics. And 3 patients with residual mild pain on last visit.

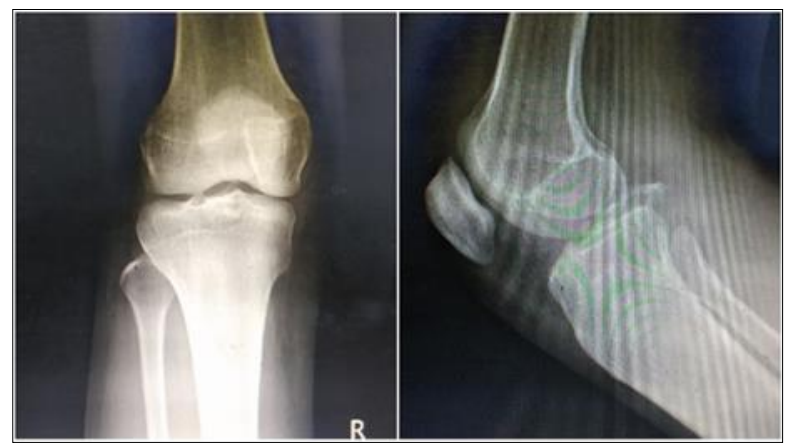

Fig 1: Anteroposterior and Lateral Plain radiograph showing PCL tibial avulsion fracture

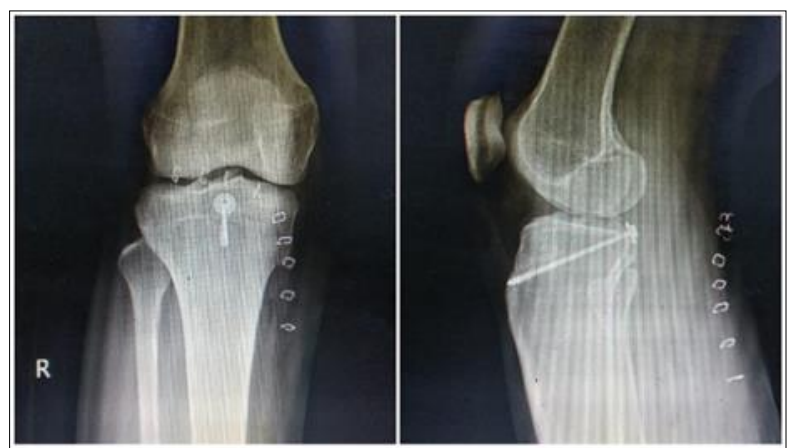

Fig 2: Anteroposterior and Lateral Plain radiograph showing PCL tibial avulsion fracture treated with Open reduction internal fixation Single canulated screw with washer POD $2^{\text {nd }}$.

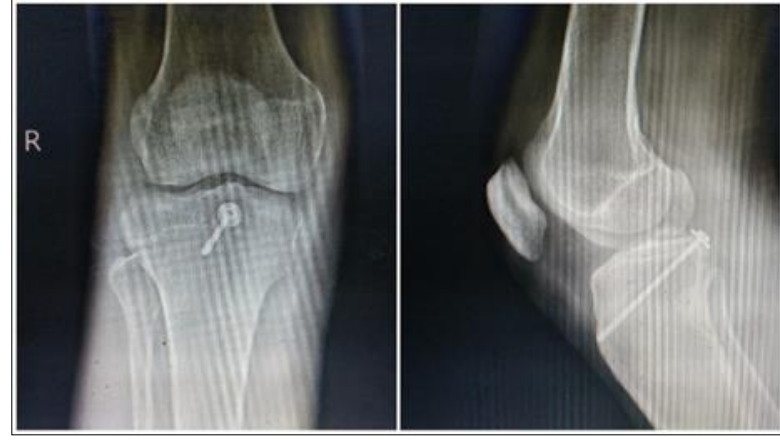

Fig 3: Anteroposterior and Lateral Plain radiograph showing PCL Tibial avulsion fracture united at 10 weeks after surgery
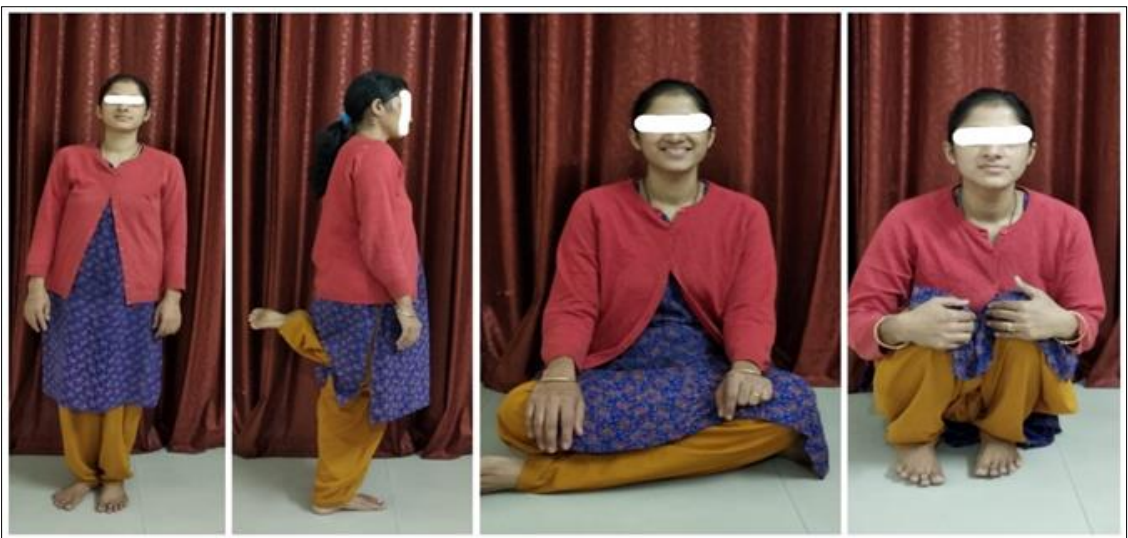

Fig 4: Showing Clinical picture of one of the operated patient from study, with excellent functional outcome

Table 1: Details of the 30 patients. Pre op- Preoperative, Post op- Postoperative

\begin{tabular}{|c|c|c|c|c|c|c|c|c|c|c|}
\hline \multirow{2}{*}{ Sr. No. } & \multirow{2}{*}{ Age in years } & \multirow{2}{*}{ Sex } & \multirow{2}{*}{ Side } & \multirow{2}{*}{ Mechanism } & \multirow{2}{*}{\begin{tabular}{|c|} 
Days before \\
Fixation
\end{tabular}} & \multirow{2}{*}{$\begin{array}{l}\text { Follow up } \\
\text { months }\end{array}$} & \multicolumn{2}{|c|}{ Lysholm Score } & \multirow{2}{*}{ Postop Laxity } & \multirow{2}{*}{ Complications } \\
\hline & & & & & & & Pre Op & Post Op & & \\
\hline Case 1 & 35 & Male & Right & RTA & 7 & 6 & 30 & 100 & Nil & Nil \\
\hline Case 2 & 40 & Male & Right & RTA & 8 & 7 & 30 & 96 & Nil & Nil \\
\hline Case 3 & 38 & Male & Left & RTA & 8 & 8 & 29 & 99 & Nil & Nil \\
\hline Case 4 & 42 & Male & Left & RTA & 9 & 6 & 35 & 95 & Nil & Superficial Infection \\
\hline Case 5 & 49 & Male & Right & RTA & 10 & 8 & 31 & 100 & Nil & Nil \\
\hline Case 6 & 45 & Male & Right & RTA & 11 & 9 & 30 & 95 & Nil & Nil \\
\hline Case 7 & 42 & Female & Right & RTA & 9 & 10 & 29 & 96 & Nil & Nil \\
\hline Case 8 & 25 & Male & Left & Sport & 7 & 9 & 30 & 100 & Nil & Nil \\
\hline \begin{tabular}{|l|} 
Case 9 \\
\end{tabular} & 29 & Male & Left & RTA & 8 & 10 & 29 & 95 & Nil & Nil \\
\hline Case 10 & 30 & Female & Left & RTA & 10 & 9 & 31 & 96 & Nil & Nil \\
\hline Case 11 & 25 & Female & Right & RTA & 12 & 8 & 30 & 88 & \begin{tabular}{|l|} 
Mild Grade 1 \\
\end{tabular} & Residual Pain \\
\hline Case 12 & 24 & Male & Left & Sport & 7 & 7 & 29 & 99 & Nil & Nil \\
\hline Case 13 & 29 & Male & Left & RTA & 8 & 6 & 28 & 100 & Nil & Nil \\
\hline Case 14 & 30 & Female & Right & RTA & 9 & 10 & 29 & 99 & Nil & Nil \\
\hline Case 15 & 37 & Male & Right & RTA & 7 & 12 & 28 & 96 & Nil & Nil \\
\hline
\end{tabular}




\begin{tabular}{|l|l|c|c|c|c|c|c|c|c|c|}
\hline Case 16 & 39 & Male & Right & RTA & 9 & 9 & 35 & 97 & Nil & Superficial Infection \\
\hline Case 17 & 42 & Female & Right & Domestic & 10 & 10 & 28 & 98 & Nil & Nil \\
\hline Case 18 & 45 & Male & Right & RTA & 11 & 9 & 29 & 100 & Nil & Nil \\
\hline Case 19 & 47 & Male & Left & RTA & 9 & 8 & 30 & 99 & Nil & Nil \\
\hline Case 20 & 38 & Male & Left & RTA & 8 & 7 & 31 & 85 & Nil & Nil \\
\hline Case 21 & 30 & Female & Left & RTA & 7 & 6 & 32 & 98 & Nil & Nil \\
\hline Case 22 & 32 & Male & Right & RTA & 10 & 10 & 30 & 97 & Nil & Nil \\
\hline Case 23 & 45 & Male & Left & RTA & 12 & 8 & 28 & 96 & Nil & Nil \\
\hline Case 24 & 50 & Female & Right & Domestic & 9 & 9 & 29 & 95 & Nil & Superficial Infection \\
\hline Case 25 & 20 & Male & Right & Sport & 7 & 8 & 25 & 85 & Mild Grade 1 & Residual Pain \\
\hline Case 26 & 22 & Male & Left & Sport & 8 & 7 & 28 & 98 & Nil & Nil \\
\hline Case 27 & 29 & Male & Right & RTA & 9 & 9 & 27 & 97 & Nil & Nil \\
\hline Case 28 & 35 & Female & Right & RTA & 10 & 8 & 29 & 100 & Nil & Nil \\
\hline Case 29 & 36 & Male & Left & RTA & 11 & 9 & 35 & 99 & Nil & Superficial Infection \\
\hline Case 30 & 38 & Male & Right & RTA & 9 & 7 & 30 & 84 & Mild Grade 1 & Residual Pain \\
\hline
\end{tabular}

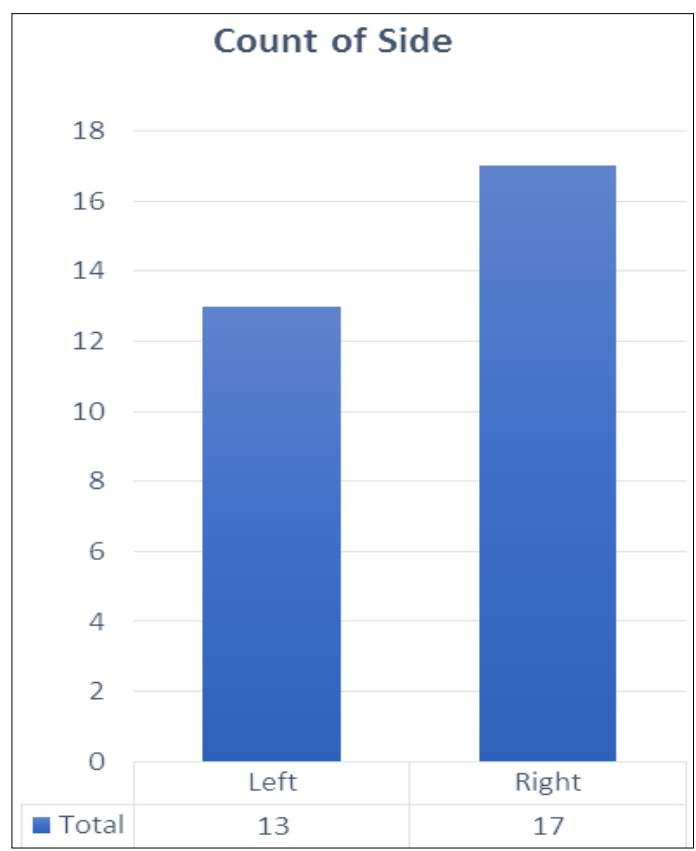

Fig 5: Comparison side affected in patients with PCL tibial bony avulsion fracture

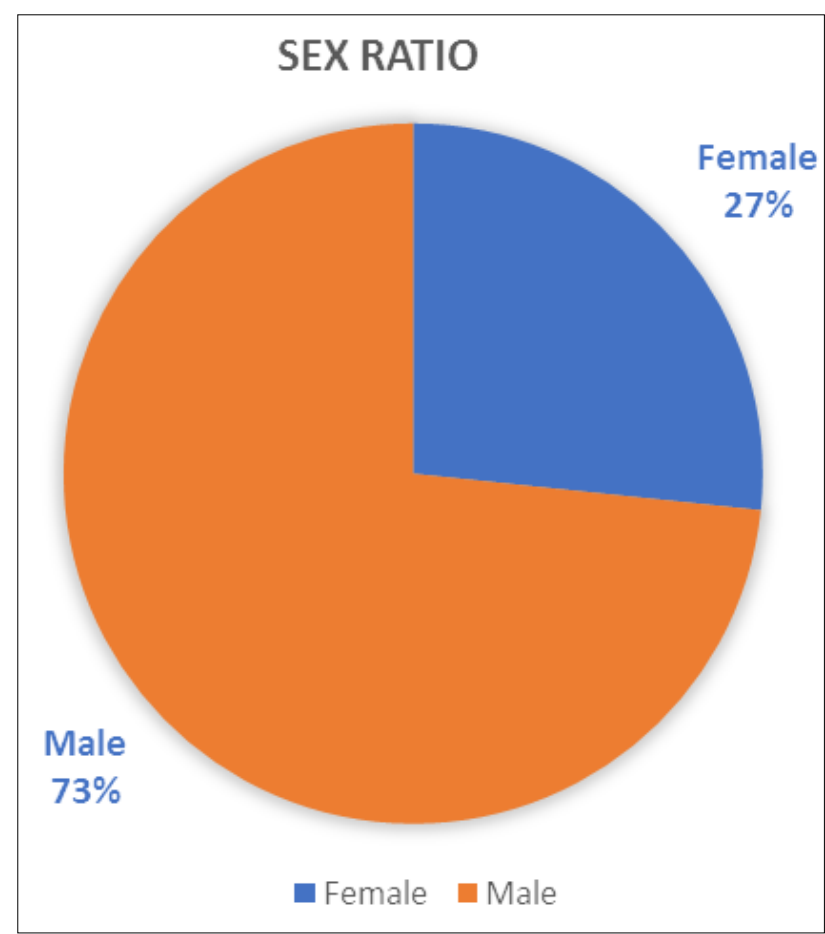

Fig 6: Pie chart: Comparison between Male and Female in patients with PCL tibial bony avulsion fracture

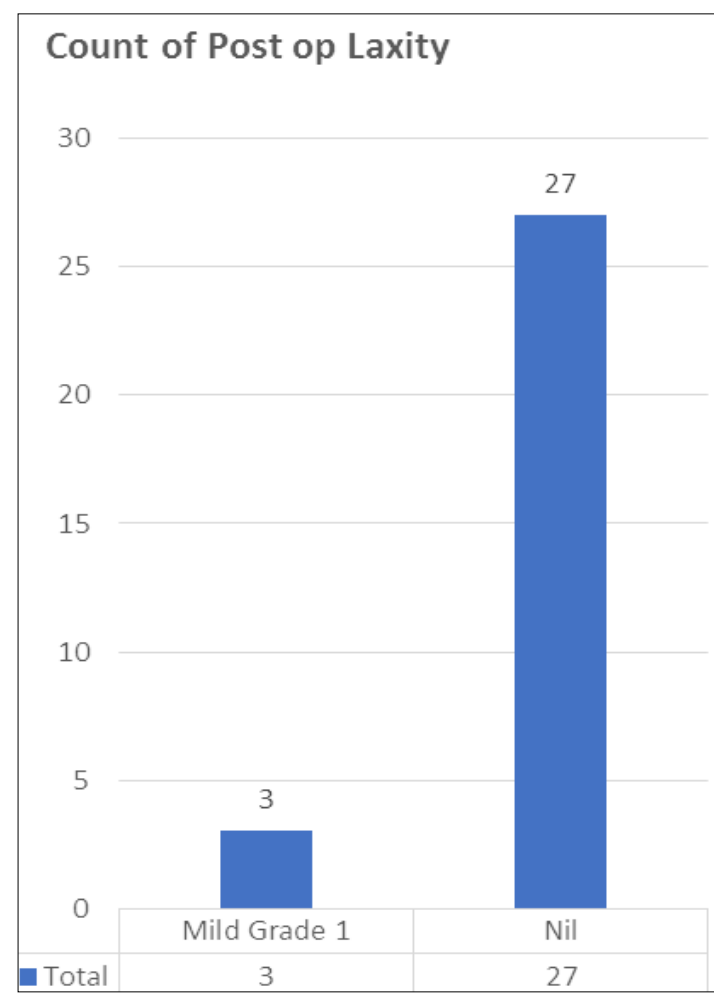

Fig 7: Comparison between postoperative finding of posterior laxity in patients with PCL tibial bony avulsion fracture 


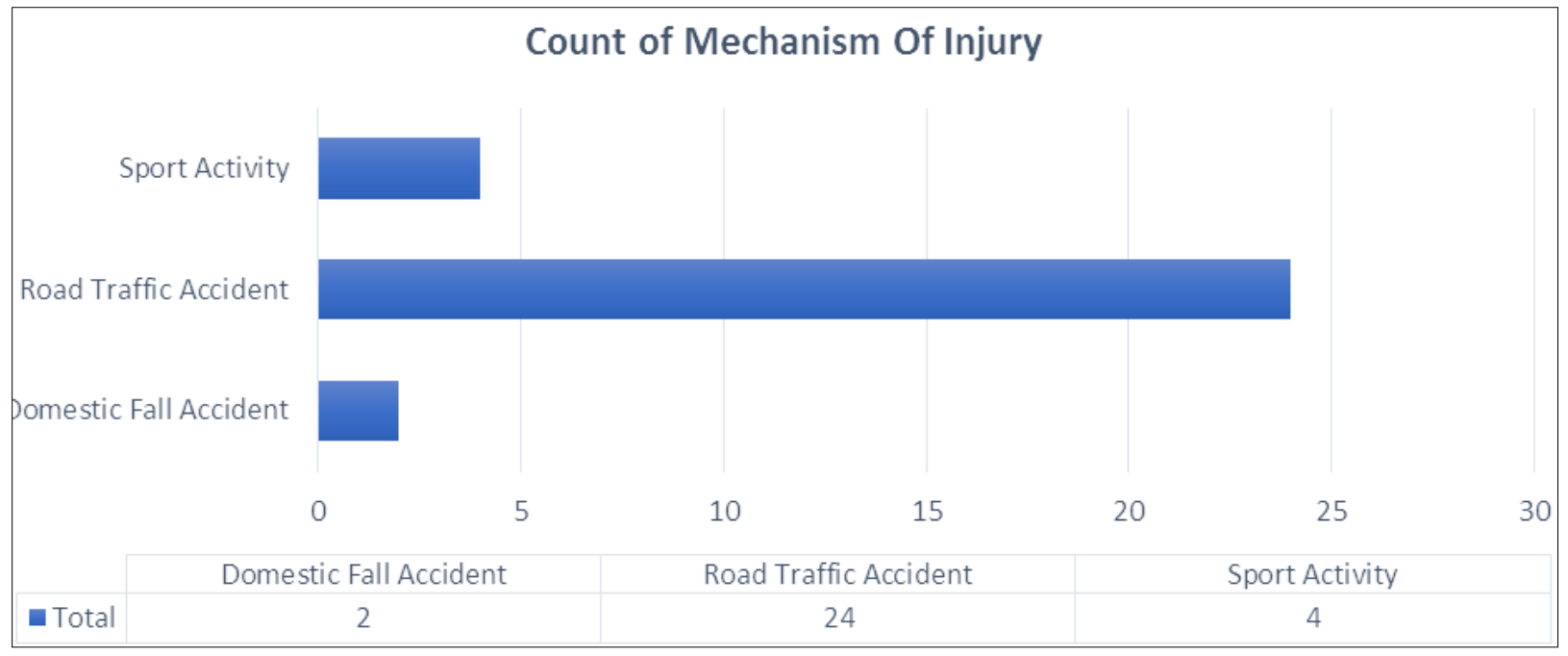

Fig 8: Comparison between mechanism of injury in patients with PCL tibial bony avulsion fracture

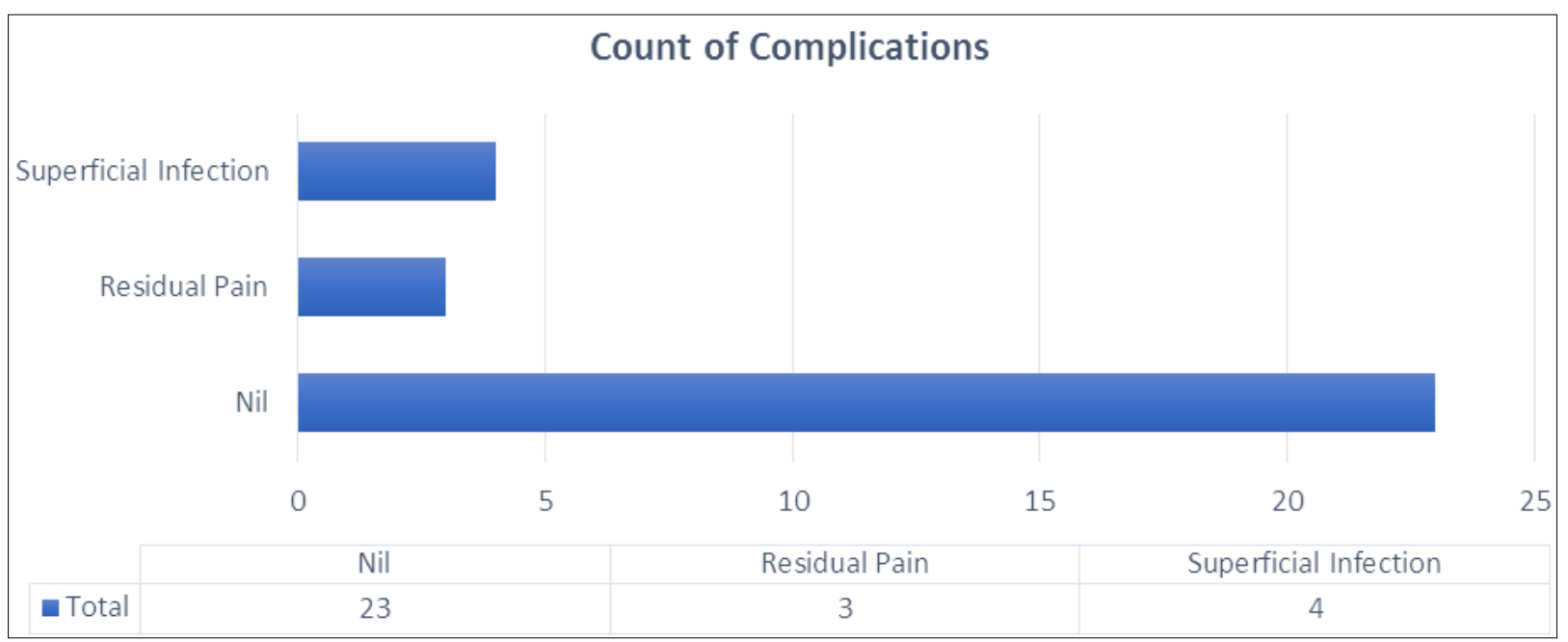

Fig 9: Comparison between postoperative complications in patients with PCL tibial bony avulsion fracture

\section{Discussion}

PCL tibial avulsion fracture is rare injury. A displaced PCL tibial avulsion fracture leads to instability of the knee and functional compromise ${ }^{[25]}$. Approaching such a fracture through an open technique ensures clear visualization of the fracture fragment with anatomical reduction and secure fixation ${ }^{[29]}$. In this surgical era, there is very little place for conservative management. Conservative management can leads to early degenerative changes, meniscus tear, and chondral damage ${ }^{[17]}$.

There are various surgical approaches have been described for the fixation of PCL avulsion fracture. The standard classical approach described by Abbott [1] was time consuming as it required handling of popliteal vessels. Later on modification were described by Trickey et al, Ogata and Burk's and Schaffer's to standard posterior approach.

Trickey [28] had made some headway in decreasing the operative time but still required the division of the medial head gastrocnemius which led to delayed rehabilitation. Ogata [23] had described the osteotomy of fibular neck which increased the complexity of the procedure.

Burk's and Schaffer's ${ }^{[4]}$ simplified the procedure and did not require division of medical head of gastrocnemius or fibular osteotomy. The post operative rehabilitation was accelerated and good functional results were obtained. We had used this approach in the management of all the cases of PCL tibial avulsion fracture injury.
Meyer ${ }^{[19]}$ had reported poor functional outcome following non-operative management of PCL tibial avulsion fracture injury.

Seitz et al ${ }^{[24]}$ had reported excellent results in their series of 26 patients treated for PCL tibial avulsion fracture with open reduction and internal fixation.

Nicandri et al ${ }^{[21]}$ had reported arthrofibrosis in only one patient of total ten patients study, when aggressive physiotherapy protocol was initiated instead of cast immobilisation.

Inoue et al ${ }^{[11]}$ had reposted some patients with posterior laxity after open reduction internal fixation of PCL tibial avulsion fracture.

Dhillon et al ${ }^{[7]}$ had reported good functional results using cannulated screws in all of their 9 cases with complete fracture healing and no pain at 6 months follow up.

Veselko et al ${ }^{[31]}$ had reported good to excellent functional results using a cannulated screw with washer.

Along with open approaches, other techniques for the treatment of PCL avulsion injuries have also been reported that use arthroscopy. The fixation of large PCL avulsion fractures has succeeded via all arthroscopic or arthroscopic assisted $\mathrm{K}$ wires or cannulated screw fixation methods $[5,6,16$, $18,31]$ and arthroscopic approaches by mean of fiber wire or suture fixation for smaller fragments have been described [14, 15, 32]. These technique evade the requirement of direct dissection in popliteal fossa, easing the fixation of smaller 
fragments in contrast to approaches performed with lag screw technique. However, arthroscopic approach are accompanied by a steep learning curve ${ }^{[32]}$ and do not completely remove risk of neurovascular bundle injury; therefore may not be suitable for all patients with PCL tibial avulsion fracture. Furthermore, arthroscopy of the damaged knee may be contraindicated in s subgroup of these patients because of severe soft tissue injury. In addition visualization may be difficult, or an impending compartment syndrome may start following an arthroscopic approach.

In our study, Lysholm score ameliorated from an Average $29.8(25-35)$ pre-operative to $96(84-100)$ postoperative (p Value $<0.001)$. Pre-operative posterior drawer testing showed that all had sag and the drawer test was positive either in grade $1(<5 \mathrm{~mm})$, grade $2(6-9 \mathrm{~mm})$ or grade $3(>10 \mathrm{~mm})$. Postoperative 3 cases had Mild grade 1 laxity.

\section{Conclusion}

Avulsion fracture of PCL tibial insertion usually constitute only a small group of Knee ligament Injury. Although several fixation techniques have been reported in literature, surgical fixation with open reduction is recommended. Dissection with Burk's and Schaffer's approach (Posteromedial Approach) is very minimal and remote the risk to neurovascular structures. Despite mild laxity in some patients, excellent functional outcome after Open fixation through Burk's and Schaffer's approach of PCL tibial avulsion which were measured with Lysholm score and subjective analysis.

\section{References}

1. Abbott LC, Carpenter WF. Surgical approaches to the knee joint. J Bone Joint Surg. 1945; 27:277-310.

2. Allen CR, Kaplan LD, Fluhme DJ, Harner CD. Posterior cruciate ligament injuries. Curr Opin Rheumatol. 2002; 14:142-9.

3. Bali K, Prabhakar S, Saini U, Dhillon MS. Open reduction and internal fixation of isolated PCL fossa avulsion fractures. Knee Surg Sports Traumatol Arthrosc. 2012; 20:315-21.

4. Burks RT, Schaffer JT. A simplified approach to the tibial attachment of the posterior cruciate ligament. Clin Orthop. 1990; 254:216-9.

5. Choi NH, Kim SJ. Arthroscopic reduction and fixation of bony avulsion of the posterior cruciate ligament of the tibia. Arthroscopy. 1997; 13(6):759-62.

6. Deehan DJ, Pinczewski LA. Arthroscopic reattachment of an avulsion fracture of the tibial insertion of the posterior cruciate ligament. Arthroscopy. 2001; 17(4):422-5.

7. Dhillon MS, Singh HP, Nagi ON. Posterior cruciate ligament avulsion from the tibia: Fixation by a posteromedial approach. Acta Orthop Belg. 2003; 69:162-7.

8. Espejo-Baena A, López-Arévalo R, Urbano V, Montañez E, Martín F. Arthroscopic repair of the posterior cruciate ligament: Two techniques. Arthroscopy. 2000; 16:65660.

9. Griffith JF, Antonio GE, Tong CWC, Ming CK. Cruciate ligament avulsion fractures. Arthroscopy. 2004; 20(8):803-12.

10. Hughston JC. The posterior cruciate ligament in knee joint stability. J Bone Joint Surg Am. 1954; 54:1045-6.

11. Inoue $M$, Yasuda $K$, Kondo $E$, Saito $K$, Ishibe $M$. Primary repair of posterior cruciate ligament avulsion fracture. The effect of occult injury in the midsubstance on postoperative instability. Am J Sports Med. 2004; 32:1230-1237.

12. Janousek AT, Jones DG, Clatworthy M, Higgins LD, Fu FH. Posterior cruciate ligament injuries of the knee joint. Sports Med. 1999; 28:429-41.

13. Kannus P, Bergfeld J, Järvinen M, Johnson RJ, Pope M, Renström $\mathrm{P}$, et al. Injuries to the posterior cruciate ligament of the knee. Sports Med. 1991; 12:110-31.

14. Kim SJ, Shin SJ, Cho SK, Kim HK. Arthroscopic suture fixation for bony avulsion of the posterior cruciate ligament. Arthroscopy. 2001; 17(7):776-80.

15. Kim SJ, Shin SJ, Choi NH, Cho SK. Arthroscopically assisted treatment of avulsion fractures of the posterior cruciate ligament from the tibia. J Bone Joint Surg Am. 2001; 83-A(5):698-708.

16. Littlejohn SG, Geissler WB. Arthroscopic repair of a posterior cruciate ligament avulsion. Arthroscopy. 1995; 11(2):235-8.

17. Lysholm J, Gillquist J. Evaluation of knee ligament surgery results with special emphasis on use of a scoring scale. Am J Sports Med. 1982; 10:150-4.

18. Martinez-Moreno JL, Blanco-Blanco E. Avulsion fractures of the posterior cruciate ligament of the knee. An experimental percutaneous rigid fixation technique under arthroscopic control. Clin Orthop Relat Res. 1988; (237):204-8.

19. Meyers MH. Isolated avulsion of the tibial attachment of the posterior cruciate ligament of the knee. J Bone Joint Surg Am. 1975; 57(5):669-72.

20. Miyasaka KC, Daniel DM, Stone ML. The incidence of knee ligament injuries in the general population. Am JKnee Surg. 1991; 4:3-8.

21. Nicandri GT, Klineberg EO, Wahl CJ, Mills WJ. Treatment of posterior cruciate ligament tibial avulsion fractures through a modified open posterior approach: operative technique and 12- to 48-month outcomes. J Orthop Trauma. 2008; 22(5):317-24.

22. O'Donoghue DH. Surgical treatment of fresh injuries to the major ligaments of the knee. J Bone Joint Surg Am. 1950; 32:721-38.

23. Ogata K. Posterior cruciate reconstruction using iliotibial band. Preliminary report of a new procedure. Arch Orthop Trauma Surg. 1980; 51:547.

24. Seitz H, Schlenz I, Pajenda G, Vecsei V. Tibial avulsion fracture of the posterior cruciate ligament: K-wire or screw fixation? A retrospective study of 26 patients. Arch Orthop Trauma Surg. 1997; 116:275-8.

25. Strobel MJ, Weiler A, Schulz MS, Russe K, Eichhorn HJ. Arthroscopic evaluation of articular cartilage lesions in posterior-cruciate-ligamentdeficient knees. Arthroscopy. 2003; 19:262-8.

26. Torisu T. Avulsion fractures to the tibial attachment of the posterior cruciate ligament: indications and results of delayed repair. Clincal Orthop Relat Res. 1979; 143:10714.

27. Trickey EL. Injuries to the posterior cruciate ligament: Diagnosis and treatment of early injuries and reconstruction of late instability. Clin Orthop Relat Res, 1980, 76-81.

28. Trickey EL. Rupture of the posterior cruciate ligament of the knee. J Bone Joint Surg Br. 1968; 50:334-41.

29. Ugutmen E, Sener N, Eren A, Beksac B, Altintas F. Avulsion fracture of the posterior cruciate ligament at the tibial insertion in a child: A case report. Knee Surg Sports Traumatol Arthrosc. 2006; 14:340-2. 
30. Veltri DM, Deng XH, Torzilli PA, Warren RF, Maynard MJ. The role of the cruciate and posterolateral ligaments in stability of the knee. A biomechanical study. Am J Sports Med. 1995; 23:436-43.

31. Veselko M, Saciri V. Posterior approach for arthroscopic reduction and antegrade fixation of avulsion fracture of the posterior cruciate ligament from the tibia with cannulated screw and washer. Arthroscopy. 2003; 19:916-21.

32. Zhao J, He Y, Wang J. Arthroscopic treatment of acute tibial avulsion fracture of the posterior cruciate ligament with suture fixation technique through $\mathrm{Y}$-shaped bone tunnels. Arthroscopy. 2006; 22(2):172-81. 